\title{
TEORIA DO CAOS NO ENSINO MÉDIO: CAMINHOS PARA INSERÇÃO DA FÍSICA MODERNA E DA EDUCAÇÃO AMBIENTAL
}

\author{
Raul dos Santos Neto ${ }^{1,2}$, Rose Mary Latini ${ }^{2}$ \\ ${ }^{1}$ Instituto Social São José;Yeshivá Colegial Machané Israel;C.E.Rui Barbosa, profraulneto@hotmail.coml \\ ${ }^{1,2}$ Mestrado Profissional em Ensino de Ciências da Saúde e do Ambiente/UNIPLI, rmlatini@uol.com.br
}

\section{Resumo}

O presente trabalho é parte integrante de uma dissertação de mestrado, em andamento, que tem por objetivo avaliar a inserção da Física Moderna no Ensino Médio, a partir da Teoria do Caos aplicada à problemática ambiental. Neste artigo procuramos compreender como os alunos percebem a questão científico-ambiental. Para tal, fizemos uso da pesquisa qualitativa pelo viés da observação participante. Os sujeitos envolvidos são alunos da segunda série, do Ensino Médio, de uma escola privada na cidade de Petrópolis. Os resultados apontam que os alunos têm dificuldades de ver as limitações da Ciência, o que traz uma incompreensão do papel da Ciência e atribuem a causa dos problemas ambientais a um homem genérico.

Palavras-chave: Ensino de Física, Teoria do Caos, Física Moderna, Educação Ambiental.

\begin{abstract}
This work is part of a dissertation, in progress, which aims to evaluate the insertion of Modern Physics in high school, from chaos theory applied to environmental issues. The aim of paper is to understand how students notice the scientific and environmental issue. The participant observation was used as technique qualitative research. The subjects were students, high school, a private school in the city of Petropolis. The results show that students have difficulty seeing the limitations of science, which has a misunderstanding of the role of science and attribute the cause of environmental problems at a generic man.
\end{abstract}

Keywords: Teaching Physics, Chaos Theory, Modern Physics, Environmental Education.

\section{Introdução}

A complexidade ambiental aponta para a necessidade de se fomentar um ensino que produza um modelo de sociedade ecológica e socialmente sustentável. A escola que está inserida nesse contexto deve cumprir seu papel de formar o educando dandolhe condições de refletir sobre as práticas da sociedade. Jacobi (2003) avalia que a reflexão sobre a complexidade ambiental gera uma oportunidade de compreensão por parte dos novos atores sociais produzindo um processo educativo mais compromissado com a sustentabilidade.

Assim, o Ensino de Ciências deve contribuir para que o aluno compreenda melhor o mundo que o cerca e, para ter, uma nova visão do mundo por meio das leis 
naturais, associando a teoria à pratica, propiciando, desta forma, uma melhor compreensão do papel da Ciência. Neste sentido é esperado que o aluno seja capaz de compreender que a Ciência apresenta certo grau de incertezas, que alguns de seus princípios são provisórios e mutáveis, e perceber como são aperfeiçoados e ampliados no decorrer de várias pesquisas. Para isso, é importante um ensino que faça a correlação entre as várias áreas do conhecimento humano, bem como as influências mútuas sofridas no decorrer do avanço tecnológico e do conhecimento. Estas são algumas das recomendações contidas na LDB/1996.

Diante de tal contexto, Guimarães e Vasconcellos (2006) destacam que a "interlocução entre a educação em ciências e a educação ambiental crítica pode alfabetizar cientificamente o cidadão e contribuir para seu engajamento no enfrentamento dos problemas socioambientais". Assim, Layrargues (2001) alega que temas ambientais devem ser tomados como geradores de reflexões para a apropriação crítica dos conhecimentos sobre as relações humanas no e com o ambiente.

Neste sentido, uma boa comunicação é de grande importância na educação, conforme nos lembra Freire (1988), ao relatar que educar não é transferência de saber, mas um encontro de sujeitos interlocutores que buscam a significação dos significados.

Vygotsky (1988) argumenta que as atividades em sala de aula são influenciadas pela sociedade, mas, ao mesmo tempo, podem, também, influenciá-la. Dentro dessa perspectiva, é necessário enfatizar a prioridade de uma formação local/global, ou seja, o aluno deve entender que ações locais podem redundar em reações globais. Portanto, é nesse universo de complexidades que precisa ser situado o aluno. E, é neste contexto, que no Ensino de Física, desejamos inserir a Teoria do Caos.

A Teoria do Caos pode ser entendida como a hipótese que explica o funcionamento de sistemas complexos e dinâmicos. Sistemas dinâmicos são aqueles que evoluem segundo uma regra que liga o estado presente aos estados passados. Em sistemas dinâmicos complexos, determinados resultados podem ser "instáveis" no que diz respeito à evolução temporal como função de seus parâmetros e variáveis. Isso significa que certos resultados determinados são causados pela ação e a interação de elementos de forma praticamente aleatória.

Este é um tópico da Física Moderna que deveria ser contemplado no Ensino de Física, não como uma curiosidade vista em programas de TV, mas, como uma Física que surge para explicar fenômenos que a Física Clássica não explica, constituindo uma nova visão de mundo. Entretanto, o Ensino de Física no Ensino Médio fica restrito à 
Física anterior ao século XX. Ou seja, pouco do que foi desenvolvido nos séculos $\mathrm{XX}$ e XXI é contemplado na grade curricular. O que contribui para afastar o Ensino de Física da realidade.

Este trabalho, que faz parte de uma dissertação de mestrado que estuda as contribuições recíprocas do Ensino de Física e da Educação Ambiental (EA), a partir da introdução da Física Moderna no Ensino Médio, tem por objetivo compreender como os alunos percebem a questão científico-ambiental.

$\mathrm{Na}$ prática docente percebemos que os alunos, quase sempre, abordam os problemas ambientais de forma catastrófica. Eles também têm dificuldade de fazer a ligação entre os conteúdos aprendidos em sala de aula com suas vivências cotidianas, principalmente no que diz respeito às responsabilidades socioambientais.

Desta forma, destacamos a possibilidade de inserir a Física Moderna no ensino médio por meio da Teoria do Caos aplicada à EA, uma vez que a citada teoria informa que pequenas ações podem redundar em grandes efeitos, ou seja, pequenas variações nas condições iniciais podem afetar consideravelmente o fenômeno estudado. Portanto, acreditamos que o trabalho pode levar o aluno a repensar suas ações e responsabilidades socioambientais, tornando-se assim um cidadão mais apto para tomadas de decisões na sociedade na qual está inserido.

\section{O Ensino de Física Moderna}

O racionalismo no ensino da Física Clássica produziu historicamente uma ideia que podemos controlar as transformações da natureza. Isso é passado quase sempre para os alunos, dando uma noção de determinismo científico. Ao ter essa visão da natureza como um "serviçal" do homem este passou a se relacionar com a mesma de forma exploratória e inconsequente. Acreditamos que a Física Moderna pode contribuir para mostrar ao homem que não temos o controle total da natureza. Muito pelo contrário, ela nos mostra o quão imprevisível pode ser o comportamento da natureza.

Podemos vislumbrar a inserção da Física Moderna no Ensino Médio como necessária para uma aproximação entre os conteúdos ensinados na escola e os assuntos vividos no cotidiano do aluno, como avaliado por Terrazzan (1992), quando salienta que o ensino da Física Moderna é fundamental para uma compreensão do mundo moderno. Por outro lado, o autor supracitado argumenta que a compatibilidade do estudo da Física Clássica e da Física Moderna, dentro de uma grade curricular de três anos do ensino médio, talvez seja o problema mais difícil a ser enfrentado, de modo a garantir a 
aceitação e, consequentemente, as chances de sucesso de uma reformulação do tipo proposto.

Assim, a Física desenvolvida nos centros de pesquisa está longe do processo de ensino e aprendizagem. Desta forma, segundo Menezes (2000), o novo Ensino Médio, desde a promulgação da nova Lei de Diretrizes e Bases da Educação Nacional (LDB), é tão somente uma definição legal, não se traduzindo em prática real e efetiva.

Sobre as razões da implementação do ensino de Física Moderna no Ensino Médio, Ostermann e Moreira (1998) salientaram as principais razões para a introdução de tópicos contemporâneos na escola básica. São elas:

- Despertar a curiosidade dos estudantes e ajudá-los a reconhecer a Física como um empreendimento humano e, portanto, mais próxima a eles.

- Conhecer o excitante mundo da pesquisa atual em Física.

- Despertar para a carreira científica, pois eles serão os futuros pesquisadores e professores de Física.

- Motivador professores com mudanças estimulantes no conteúdo do curso.

- A Física Moderna é considerada conceitualmente difícil e abstrata; mas, resultados de pesquisa em ensino de Física têm mostrado que, além da Física Clássica ser também abstrata, os estudantes apresentam sérias dificuldades conceituais para compreendê-la.

Stannard (1990) justifica a atualização curricular ao relatar um levantamento feito com estudantes universitários que mostrou que é a Física Moderna que mais os influencia na decisão de escolher a Física como carreira. O autor também relata que um terço dos alunos que entrevistou, em doze anos de pesquisa, já havia ouvido falar em buracos negros e tinha uma vaga ideia do que se tratava. Um número razoável relacionava Big Bang com origem do universo. O autor ainda revela que eles tinham um conhecimento aprendido pela televisão e através de filmes de ficção científica.

Dentro de uma linha tradicional de Ensino de Física, o caráter não linear do desenvolvimento científico não é visualizado pelos alunos, tendo em vista a abordagem priorizada na resolução de problemas. Fatos e descobertas e as dificuldades que originaram a crise da Física Clássica, praticamente não são mencionadas pelo professor de Física, bem como a profundas diferenças conceituais entre a Física Clássica e a Moderna.

Concluímos, dessa forma, que o ensino de Física Moderna no Ensino Médio é uma forma de valorizar o contexto altamente tecnológico em que estão imersos os alunos. Logo, deve ser visto como uma forma de aproximar os conteúdos à vivência do aluno e, principalmente, como fator de integração do conhecimento tão fragmentado pelo racionalismo moderno, dando ao aluno uma visão interdisciplinar.

\section{Teoria do Caos e Determinismo}

A Teoria do Caos vem ganhando espaço na comunidade científica, bem como em outros meios, devido ao fato de trazer um conhecimento mais detalhado dos mecanismos que cercam a evolução dos eventos futuros. Tal fato é de grande valia para pesquisas nos campos da economia, política e ciência de base, o que aponta para importância de compreendermos melhor como essa Teoria pode auxiliar na 
compreensão dos problemas ambientais, sendo, portanto um facilitador do ensino de Ciências num viés ambiental.

A origem da Teoria do Caos surge com a preocupação em definir determinismo como a concepção filosófica que afirma serem todos os acontecimentos, inclusive vontades e escolhas humanas, causados por acontecimentos anteriores, ou seja, o homem é fruto direto do meio, ou seja, os acontecimentos futuros são determinados por causas anteriores ao fenômeno.

Hunnex (2003), ao classificar as correntes filosóficas no que tange às responsabilidades sobre os atos e escolhas pessoais, explica que no determinismo rígido tudo o que acontece tem uma causa, ou seja, existe um conjunto de condições tais que, se as condições forem repetidas, o acontecimento seria igualmente repetido. Portanto, dá uma ideia de lei que rege a situação. Como definiu Aristóteles, a causalidade é uma verdade priori, ou seja, o mundo é um mecanismo.

Já no determinismo brando, a corrente filosófica de Hume e Mill, a causalidade é uma generalização descritiva, portanto, empírica acerca do mundo, ou seja, os atos evitáveis são livres; os atos inevitáveis (inadvertidos, etc.) não são livres. Portanto, não são a priori. Logo, a causalidade não é compulsão nem uma obrigação. O autor ainda explica que no fatalismo, ou acaso, o fato ocorreu por que tinha que acontecer, não era possível evitar. Não há causas determináveis. A visão apocalíptica pode ser descrita como fatalista.

Sob o ponto de vista científico, o determinismo constitui um princípio da ciência experimental que se fundamenta pela possibilidade da busca das relações constantes entre os fenômenos. Para os deterministas, todos os acontecimentos do universo estão de acordo com as leis naturais, ou seja, que todo fenômeno é condicionado pelo que precede e acompanha, propondo sempre uma investigação na causa dos fenômenos, sem aceitar que aconteceu porque tinha de acontecer.

Moreira (1992) afirma que já na antiguidade clássica se discutia a relação entre determinismo e acaso para entender os fenômenos naturais. Com isso, Tales de Mileto conseguiu prever um eclipse em 585 a.C. Esse acontecimento corroborou para um determinismo científico. Relata que Newton, ao avaliar a questão da gravitação, acreditava que as previsões feitas pelo conhecimento das forças e das equações de movimento têm alto grau de precisão. Porém, elas são parciais, porque as forças somente não determinam o curso natural das coisas. O autor comenta que, ao abordar questões mais complicadas que o do movimento de sistemas todos os cientistas se deparavam com uma matemática estranha. Nesse período, o pêndulo era muito utilizado como demonstração da periodicidade e o comportamento previsível na natureza. Porém, no caso da mecânica dos fluidos, gravitação de três corpos e outros fenômenos eram deixados de lado. 
Moreira op cit lembra que mesmo com o surgimento da probabilidade de Fermat e Pascal, o tratamento era determinista, ou seja, dava uma idéia de conexão causal. O autor ainda afirma que isso ocorreu devido à limitação do conhecimento humano, pois a ignorância das causas e de dados era compensada pelo uso da probabilidade. O que tornava possível submeter ao método científico questões morais e de ordem social.

No final do século XIX filósofos e cientistas questionavam o caráter determinista no sentido físico, ainda que aceitassem a mecânica newtoniana. Moreira (op cit) lembra que Maxwell atribui um caráter de incerteza intrínseca ao conhecimento estatístico, o que rompia com a visão casualística nos cálculos probabilísticos. $\mathrm{O}$ autor lembra que Maxwell fala de domínios de atração (bacias), em que um desvio imperceptível será suficiente para levar os sistemas a cair em domínios diferentes. Lembramos também que Poincaré introduz a noção de estudo qualitativa das soluções de sistemas dinâmicos, onde a predição se torna impossível e temos um fenômeno fortuito. Poincaré declara que a sensibilidade do sistema às condições iniciais e a complexidade das causas é causa dessa imprevisibilidade.

Somando-se a isso temos o surgimento da relatividade de Einstein que mostrava um espaço-tempo diferente do modelo de Newton. Portanto, temos as condições para o surgimento da Teoria Moderna do Caos, principalmente do Caos determinístico.

\section{Metodologia}

Procurando compreender como os alunos percebem a questão científicoambiental fizemos uso da pesquisa qualitativa pelo viés da observação participante. Os sujeitos envolvidos são 23 alunos da segunda série do Ensino Médio de uma escola privada da cidade de Petrópolis. A escolha se justifica pelo fato do conteúdo programático da escola conter uma análise sobre Entropia, que pode ser simploriamente definido como a medida do Caos num sistema, o que facilitaria a abordagem sobre o Estudo da Teoria do Caos.

Mazzoti e Gewandsznajder (1998) relatam que as pesquisas qualitativas possuem características multimetodológicas, utilizando um número variado de métodos e instrumentos de coleta de dados. Entre os mais aplicados, estão a entrevista (individual e grupal), a análise de documentos e a observação participante.

Richardson (1999) analisa que a observação participante possibilita o pesquisador analisar a realidade social que o rodeia. Uma das vantagens da utilização dessa técnica é a possibilidade de um contato pessoal do pesquisador com o objeto de 
investigação, permitindo acompanhar as experiências diárias dos sujeitos e apreender o significado que atribuem à realidade e às suas ações.

A matéria prima da investigação qualitativa é a palavra que expressa a fala cotidiana, seja nas relações afetivas e técnicas, seja nos discursos intelectuais, burocráticos e políticos. Dessa forma, Bakhtin (1986), declara que existe uma onipresença social e universal nas palavras. Pois elas são construídas num contexto de material ideológico, servindo de trama a todas as relações sociais. $\mathrm{O}$ autor ainda avalia que as palavras podem ser consideradas como indicadores mais sensíveis das transformações sociais, mesmo daquelas que ainda não tomaram formas. Ele também acredita, que elas atuam como meio no qual se produzem lentas acumulações quantitativas, ou seja, são capazes de registrar as fases transitórias mais íntimas e mais efêmeras das mudanças sociais.

Nesse contexto de observação, iniciamos o trabalho com a aplicação de um questionário introdutório, que segue abaixo, com intuito de verificar como os alunos pensavam e refletiam sobre a questão ambiental e avaliar a sua percepção sobre o determinismo científico, ou seja, se para eles existe uma causa na mesma proporção para cada efeito.

1. Comente a frase a serguir revelando se você concorda ou não e por que -"Nenhum efeito é quantitativamente maior e/ou qualitativamente superior à causa".

2. Como você pensa o futuro. Algo aberto e passível de escolhas, ou determinado pelas experiências da vida. Por exemplo, um bandido escolheu a vida do crime, ou as circunstâncias determinaram seu padrão de comportamento?

3. Pelo que você já estudou de Ciências, comente o caso a seguir: No caso de um papel em queda, se ele sempre for abandonado da mesma altura ele cairá da mesma forma todas vezes? De que forma ele pode cair? Explique seu ponto de vista (com suas palavras).

4. O que você entende por processo reversível? Por exemplo, Suponha que temos água vermelha, com tinta, e água branca, sem tinta, em um tanque, com uma separação. Removendo delicadamente a separação, a água começa dividida, vermelha de um lado e branca do outro. Com o passar do tempo, a água vai gradativamente misturando-se, e no final temos água avermelhada, com a tinta uniformemente distribuída. Agora, mesmo que observemos a mistura por um longo período de tempo, ela vai separar-se espontaneamente ou não? Comente o caso.

5. Comente sobre a problemática ambiental?

A temática das questões variou entre a relação causa x efeito, onde se buscava avaliar a forma de pensar do aluno no que diz respeito ao determinismo e o acaso. Dessa forma, buscou-se saber até que ponto o aluno acredita que tudo é resultado de uma lei rígida. O objetivo das duas primeiras questões era criar situações onde acreditamos que o aluno iria revelar como ele vê o mundo e suas leis. As questões 3 e 4 
buscavam avaliar como o aluno entende a reversibilidade dos fenômenos da natureza, bem como visualizar se ele tem uma noção intuitiva de caos, ou seja, da falta de controle em certos experimentos. O objetivo da última pergunta era perceber como o aluno se posiciona diante de problemas ambientais no que tange às responsabilidades pessoais, à possibilidade de reversão dos problemas e a ligação desses problemas com a forma de vida da comunidade na qual ele está inserido.

\section{Resultados e Discussão}

Como salientam Silva e Carvalho (2006), as questões de natureza não-científica devem assumir uma importância crucial na discussão de temas controversos relacionados com as implicações sociais e ambientais da aplicação da Ciência e da Tecnologia. Nesse sentido, entendemos ser possível averiguar se os argumentos da racionalidade científica possibilitam, ou não, explorar de forma mais ampla as complexidades inerentes à temática ambiental.

Quando observamos o resultado obtido na primeira pergunta, percebemos que ele revela que grande parte dos alunos acreditava que para todo efeito há uma causa proporcional, onde muitos alunos citaram a $3^{\mathrm{a}}$ lei de Newton:

A toda ação corresponde uma reação de mesma intensidade. A causa tem um efeito que é quantitativamente, e qualitativamente, correspondente à causa, não maior. (Aluno JB)

Contudo, outros alunos mostraram que acreditam que para toda ação há uma reação, mas não na mesma proporção, ou seja, não acreditam num determinismo rígido. O que nos leva a pensar, que nesse sentido, os argumentos da racionalidade científica possibilitam explorar de forma mais ampla as complexidades inerentes à temática ambiental. Dois alunos ainda separaram o fenômeno quantitativo do qualitativo, onde o primeiro poderia ser proporcional, o segundo não. A seguir são transcritas as falas:

Isso é muito relativo, pois dependendo da causa o efeito pode ser maior ou menor. (Aluna D.V.)

Se um ladrão rouba alguém, ele receberá como conseqüência sua prisão. Porém, ele pode ter sua pena reduzida ou até mesmo não ser preso.(Aluno J.T.)

Os efeitos não podem ser proporcionais por que existem vários tipos de causas, ou seja, dependendo da causa pode ser igual, maior ou menor seus efeitos.(Aluno D.V.)

O aluno P.H. ainda faz uma análise diferente dizendo que "só é proporcional nas leis naturais" Para ele, do ponto de vista social isso não vale. Os efeitos no último caso podem ser maiores que as causas. Portanto, as falas apontam para um determinismo 
rígido, ou seja, podemos ter o controle total dos fenômenos. Dessa maneira, podemos inferir que os alunos apresentam forte influência da ciência clássica, fruto e avalista de uma cultura e uma época nas quais a humanidade, parece ter tido êxito ao apresentar um modelo que submetia inteiramente a natureza ao seu controle. Desta forma, ela sempre imaginou que tais sistemas evoluíssem de forma contínua e perfeitamente antecipável em qualquer ponto do futuro, isto é, sempre se supôs que sistemas determinísticos só pudessem apresentar trajetórias temporais perfeitamente previsíveis.

Portanto, acreditamos que os alunos estão imersos dentro do raciocínio clássico, onde se supunha que pequenas diferenças na disposição dos componentes do sistema no início de sua trajetória ou desvios ao longo de sua trajetória temporal teriam impacto que pode ser desconsiderado sobre o resultado final. Dessa forma, a maior parte dos alunos simplesmente descarta as múltiplas variáveis existentes nos fenômenos.

Por isso, Silva e Carvalho (2006) relatam que as críticas direcionadas ao ensino de Ciências Naturais, em geral, e ao Ensino de Física, em particular, tanto no nível médio quanto no nível superior, apontam para um ensino voltado aos aspectos conceituais da Ciência, com ênfase numa descrição matemática dos fenômenos. Além disso, os conteúdos trabalhados nesses cursos tendem a enfatizar aspectos factuais desvinculados de um contexto mais amplo e de situações concretas vivenciadas pelos estudantes.

Isso fica mais claro quando avaliamos as respostas da segunda pergunta, onde houve uma abordagem sociológica. Nesta situação, as respostas apontam que a maior parte dos alunos acredita num determinismo brando, ou seja, sob certas circunstâncias não temos o controle da situação. Entretanto, outros alegaram que foi fatalidade o ocorrido, e outro grupo apresentou um determinismo rígido, ou seja, alegaram que não havia outra opção devido às condições estabelecidas. Logo, nesse tipo de contexto os alunos mudaram o padrão de respostas.

Avaliamos que as duas primeiras perguntas nos ajudaram a perceber que os alunos consideram os fenômenos físicos controláveis. Logo, elas são decorrentes de leis rígidas. Portanto, podemos ter o controle pleno da natureza se conhecermos suas leis e aplicá-las. Contudo, no que diz respeito às questões sociológicas eles não são tão rígidos. O que nos mostra que eles têm dificuldades de ver as limitações da ciência, o que traz uma incompreensão do papel da Ciência.

$\mathrm{Na}$ terceira pergunta a fala dos alunos revelou que quase todos observaram que outros fatores influenciavam no fenômeno, e, que estes iriam produzir resultados 
diferentes. Nesse ponto, percebemos que quando trazemos o estudo para problemas de fácil experimentação cotidiana, sua noção de realidade das múltiplas variáveis, mesmo que eles não soubessem explicitar quais eram, revelou uma noção intuitiva de Caos nos fenômenos naturais. Nessa concepção, os alunos levaram em consideração que instabilidade dos resultados é consequência de uma grande sensibilidade a perturbações (ruídos) e erros. Isso pode ser notado quando eles relatam que os resultados podem ser imprevisíveis ou aleatórios, ou seja, ocorrendo ao acaso:

Não cairá do mesmo jeito. Porém, não é possível determinar todas as formas como ele cairá, pois nunca será da mesma forma, ou seja, ele nunca se repetirá. Há vários elementos interferindo no fenômeno, como o vento e gravidade. O mesmo acontece em nossas vidas, onde vários fatores fogem ao nosso controle. (Aluno JM) Ele cairá de várias formas, pois será influenciada por muitos fatores. (Aluno J.L). Acredito que o formato do papel, bem como a textura irá fazer cair de maneiras diferentes quanto interagirem com o ar. (Aluno D.V.)

Isso significa que certos resultados determinados são causados pela ação e a interação de elementos de forma praticamente aleatória. O mesmo resultado foi obtido quando questionados sobre a possibilidade da reversibilidade de processos. Porém, muitos alunos acreditavam que determinados fenômenos podem ser reversíveis, dentre os quais, metade acreditava que só para fenômenos Físicos, e não para Químicos (ainda não estudaram Equilíbrio Químico). Essa visão de possibilidade de reversibilidade pode ser entendida como algo positivo, pelo menos do ponto de vista ambiental:

Sim, existem processos que podem voltar ao estado normal, ou seja, serem reversíveis. Porém, só para fenômenos Físicos. A densidade diferente dos materiais fará que se separem sozinhos. (Aluno G.B)

Como não é um fenômeno químico, pode ser reversível sim. (Aluno J.B)

Contudo, acreditamos que essa forma de pensar seja alterada quando os alunos estudarem Equilíbrio Químico e Entropia, o que sugere que a ciência pode contribuir para o entendimento de questões socioambientais.

Na quinta questão observamos que quase a totalidade dos alunos falou sobre os problemas ambientais da forma que são noticiados nas mídias. Lembraram do aquecimento global, do desmatamento, do problema do lixo, etc. Também relataram que a causa desses problemas é a forma de viver de nossa sociedade, culpando a globalização e o consumismo exagerado da sociedade capitalista. Somente um aluno declarou que o processo era irreversível, só nos cabendo agora atenuar as conseqüências: 
Devido à falta de conhecimento e de conscientização, chegamos a tal ponto em que não há volta. A única coisa que podemos fazer agora e amenizar tal processo. (Aluno P.D)

Os problemas ambientais são diversos. Os seres humanos desperdiçam e exploram excessivamente, e sem inteligência, os recursos da natureza. Com isso, várias catástrofes ocorrem. É uma forma da natureza responder, ou seja, a toda ação vem uma reação.(Aluno I.P.)

Num mundo globalizado e capitalista as pessoas só se importam com bens materiais. Por isso, os problemas cada dia aumentam mais. (Aluno R.M.)

As falas sugerem a não reversibilidade de processos e um determinismo rígido já que a toda ação corresponde uma reação, reforçando uma ideia de leis rígidas presentes na natureza. Outra observação que pode ser feita é quanto à responsabilidade individual, pois em nenhum momento eles fizeram reflexão sobre atos pessoais. Sempre o homem, ou a humanidade, no sentido mais amplo eram os responsáveis.

Outro fator importante a ser trabalhado é que eles associam os danos à natureza como algo recente da sociedade capitalista. Não levaram em consideração outros impactos ambientais de tempos anteriores à revolução industrial, impactos ambientais no comunismo ou outro sistema de governo, nem a fatores meramente físicos como queda de meteoros (principal explicação para extinção dos dinossauros), vulcões, etc.

\section{Considerações finais}

O trabalho de pesquisa para a dissertação de mestrado teve continuidade pela introdução da Teoria do Caos usando para tal o filme Efeito Borboleta, bem como vários exemplos da aplicação dessa área da Física em outros ramos do conhecimento. Seguimos com a introdução do conceito de Entropia, uma vez que ela pode ser definida como uma grandeza termodinâmica geralmente associada ao grau de desordem. Ela mede a parte da energia que não pode ser transformada em trabalho. É uma função de estado cujo valor cresce durante um processo natural em um sistema fechado. Também realizamos experiências com um pêndulo magnético para exemplificar e ampliar o conceito de Caos na Física e seguimos com debates, discussão de texto e exibição de vídeos.

Acreditamos que após essas noções introdutórias da Teoria do Caos os alunos tenham mais condições de avaliar que a Física Moderna está mais próxima de suas vidas cotidianas do que eles imaginam. Também acreditamos que a noção racionalista de controle e uso indiscriminado da natureza será revisto, uma vez que o ensino da Teoria 
do Caos clarifica para os estudantes que esse controle é válido para curtos espaços de tempo.

Como avalia Silva e Carvalho (2006), em relação ao ensino de Ciências Naturais devem ser vistas, como relevante, a possibilidade de realizar trabalhos educativos que objetivem uma alfabetização científica crítica. Assim, os alunos terão a possibilidade de ter uma explanação que faça uma discussão de aspectos relativos à epistemologia da Ciência, de forma a abarcar questões sobre as possibilidades e os limites deste tipo de conhecimento.

É nesse contexto que os alunos devem ser inseridos, ou seja, as implicações sociais e ambientais da Ciência e da Tecnologia apresentam um grande potencial para clarificarmos a complexidade presente na realidade. O que torna imprescindível um diálogo de saberes.

\section{Referências}

BAKHTIN, M., 1986. Marxismo e Filosofia da Linguagem. $3^{a}$ ed., São Paulo: Hucitec. GUIMARÃES, Mauro.e VASCONCELLOS, Maria das Mercês N. Relações entre Educação Ambiental e Educação em Ciências na complementaridade dos espaços formais e não formais de educação. Educar em Revista, Curitiba, n. 27, v. 27, 2006.

HUNNEX, M. Filósofos e Correntes Filosóficas. Ed Vida. São Paulo. 2003

JACOBI, P. Educação Ambiental, Cidadania e Sustentabilidade. Cadernos de Pesquisa, n. 118, P. 189-205, março/ 2003.

LAYRARGUES, P. A resolução de problemas ambientais locais deve ser um tema-gerador ou atividade-fim da educação ambiental? In: REGOTA, M(ORG). Verde cotidiano, meio ambiente em discussão. Rio de Janeiro, DP\&D. 2001.

MENEZES, L. C. Física para o Novo Ensino Médio .Revista Física na Escola, v. 1, n. 1, 2000. MOREIRA, I. C. Os Primórdios de Caos Determinístico. Revista Ciência Hoje. Vol. 14 - No 80 (p.11-16). 1992.

OSTERMANN, F., MOREIRA, M. A. Tópicos de física contemporânea na escola média brasileira: um estudo com a técnica Delphi. In: Encontro de Pesquisa em Ensino de Física, 6. 1998, Florianópolis. Atas. Florianópolis: Imprensa UFSC, 1998. 19p. [Seção de Comunicações Orais] 1 CD-Rom

OSTERMANN, F e MOREIRA, M. A. Uma Revisão Bibliográfica Sobre a Área de Pesquisa "Física Moderna e Contemporânea no Ensino Médio". Investigações Em Ensino de Ciências ISSN 1518-8795

STANNARD, R. Modern physics for the young. Physics Education, Bristol, v. 25, n. 3, p. 133, May 1990.

SILVA, L. F. e CARVALHO, L. M. O Ensino de Física a Partir de Temas Controversos: A produção de energia em larga escala. Araraquara-SP: Faculdade de Ciências e Letras de Araraquara-UNESP. 2006.

TERRAZZAN, E. A. A inserção da física moderna e contemporânea no ensino de física na escola de $2^{\circ}$. grau. Caderno Catarinense de Ensino de Física, Florianópolis, v. 9, n. 3, p. 209214, dez. 1992

VYGOTSKY, L. S.. A Formação Social da Mente. São Paulo, Martins Fontes, 132 p. 1984 